\title{
Reciprocal Changes in the Expression of Transcription Factors GATA-4 and GATA-6 Accompany Adrenocortical Tumorigenesis in Mice and Humans
}

\author{
Sanne Kiiveri, ${ }^{1}$ Susanna Siltanen, ${ }^{1}$ Nafis Rahman, ${ }^{2}$ \\ Malgorzata Bielinska, ${ }^{3}$ Veli-Pekka Lehto, ${ }^{4}$ Ilpo T. Huhtaniemi, ${ }^{2}$ \\ Louis J. Muglia, ${ }^{3,5}$ David B. Wilson, ${ }^{3,5}$ and \\ Markku Heikinheimo ${ }^{1,3}$ \\ ${ }^{1}$ Children's Hospital, University of Helsinki, Helsinki, Finland \\ ${ }^{2}$ Department of Physiology, University of Turku, Turku, Finland \\ ${ }^{3}$ Department of Pediatrics, Washington University, St. Louis, Missouri, \\ U.S.A. \\ ${ }^{4}$ Department of Pathology, University of Oulu, Oulu, Finland \\ ${ }^{5}$ Department of Molecular Biology and Pharmacology, Washington \\ University, St. Louis, Missouri, U.S.A.
}

Accepted June 10, 1999.

\begin{abstract}
While certain genetic changes are frequently found in adrenocortical carcinoma cells, the molecular basis of adrenocortical tumorigenesis remains poorly understood. Given that the transcription factors GATA-4 and GATA- 6 have been implicated in gene expression and cellular differentiation in a variety of tissues, including endocrine organs such as testis, we have now examined their expression in the developing adrenal gland, as well as in adrenocortical cell lines and tumors from mice and humans. Northern blot analysis and in situ hybridization revealed abundant GATA- 6 mRNA in the fetal and postnatal adrenal cortex of the mouse. In contrast, little or no GATA-4 expression was detected in adrenal tissue during normal development. In vivo stimulation with ACTH or suppression with dexamethasone did not affect the expression of GATA-4 or GATA- 6 in the murine adrenal gland. To assess whether changes in the expression of GATA-4 or GATA-6 accompany adrenocortical tumori-
\end{abstract}

genesis, we employed an established mouse model. When gonadectomized, inhibin $\alpha / S V 40$ T-antigen transgenic mice develop adrenocortical tumors in a gonadotropin-dependent fashion. In striking contrast to the normal adrenal glands, GATA-6 mRNA was absent from adrenocortical tumors or tumor-derived cell lines, while GATA-4 mRNA and protein were abundantly expressed in the tumors and tumor cell lines. Analogous results were obtained with human tissue samples; GATA-4 expression was detected in human adrenocortical carcinomas but not in normal tissue, adenomas, or pheochromocytomas. Taken together these results suggest different roles for GATA-4 and GATA- 6 in the adrenal gland, and implicate GATA- 4 in adrenal tumorigenesis. Immunohistochemical detection of GATA-4 may serve as a useful marker in the differential diagnosis of human adrenal tumors.

\section{Introduction}

Adrenocortical carcinoma (ACC) is a rare tumor affecting both children and adults. In the United
States the incidence is approximately 3 per million children less than 16 years of age (1) and $0.5-2$ per million adults (2), although a higher 
incidence has been reported in some countries (3). The majority of pediatric patients $(>95 \%)$ exhibit virilization (3), and Cushing's syndrome is common $(>70 \%)$ in pediatric and adult patients $(3,4)$. Overall ACC represents $0.2 \%$ of the causes of death from cancer (2). The mainstay of treatment for ACC is surgery $(3,5,6)$; when total resection is possible, the one year survival rate in pediatric patients is approximately $65 \%$ (3). Antineoplastic agents have been used with limited success in cases of advanced disease $(5,7,8)$.

The molecular mechanisms underlying adrenocortical tumorigenesis are not known. The clonality of adrenocortical tumors has been examined using $\mathrm{X}$-chromosome inactivation analysis on human pathologic samples; most adrenal adenomas and carcinomas are monoclonal in nature, whereas diffuse and nodular adrenal hyperplasias are polyclonal (9). ACC is found in association with the Li-Fraumeni (10) and Beckwith-Wiedemann (11) syndromes, suggesting that malignant transformation may be influenced by the p53 gene $(1,12,13)$ or imprinted genes at the $11 \mathrm{pl} 5$ locus such as p57KIP2 (14). In addition, allelic loss of the $R B$ gene has been noted in ACC samples, indicating that this gene may be involved in tumorigenesis (13). Multiple endocrine neoplasia type 1 (MEN-1) can involve the adrenal cortex (15), and ACC cells express markers typical of neuroendocrine cells, such as synaptophysin, neuron specific enolase, and vimentin, implying that ACC may originate from neuroendocrine foci within the adrenal cortex (16).

A transgenic mouse model of adrenal tumorigenesis has been recently described; mice bearing an inhibin $\alpha$-subunit promoter/Simian Virus $40 \mathrm{~T}$-antigen fusion gene develop gonadal tumors originating from granulosa or Leydig cells (17-19). When these transgenic mice are gonadectomized before puberty, they develop malignant adenocorticortical carcinomas (20). These adrenal tumors do not appear in non-gonadectomized animals. If functional gonadectomy is induced by administration of a GnRH antagonist or by cross-breeding the transgenic mice into the

This work was performed at Children's Hospital, University of Helsinki and Department of Pediatrics, Washington University of St. Louis. S. Kiiveri and S. Siltanen contributed equally to this work.

Address correspondence and reprint requests to: Dr. Markku Heikinheimo, Children's Hospital, University of Helsinki, Stenbäckinkatu 11, 00290 Helsinki, Finland. Phone: 358-9-47174768; Fax: 358-9-47175299; E-mail: markku.heikinheimo@helsinki.fi hypogonadotropic hpg genetic background, neither gonadal nor adrenal tumors appear (21). This led to the hypothesis that tumor development is related to elevated gonadotropin secretion, which is the most obvious difference between the surgical and functional gonadectomy models (22). The adrenal tumors and a cell line $(\mathrm{C} \alpha \mathrm{l})$ derived from them were found to express functional LH receptors, and hCG treatment of the cells stimulated their proliferation and steroid production (22). On the basis of this and other data it has been proposed that expression of the potent oncogene, T-antigen, in adrenocortical cells allows a trophic hormone to function as a tumor promoter. While obvious differences exist between this mouse model and ACC in humans, certain similarities are noteworthy. Adrenal carcinomas in humans and the transgenic mice express a number of common markers, including neuroectodermal markers and steroidogenic enzymes $(16,20,22)$. Moreover, human adrenocortical tumors responsive to gonadotropins have been described $(23,24)$. These conserved features make this transgenic model potentially useful for identifying factors critical for adrenocortical tumorigenesis in humans.

GATA-4 and GATA- 6 belong to a family of zinc finger transcription factors termed the GATA-binding proteins, which regulate gene expression, differentiation, and cell proliferation in a variety of tissues $(25,26)$. Within the endocrine system, GATA-4 and/or GATA- 6 are expressed in the female and male gonad (27-33), and developing hypothalamus $(34,35)$. In ovary, GATA-4 expression localizes to granulosa cells of primary and early antral follicles, whereas GATA-6 is present in late antral follicular cells and luteal glands (31). In addition, the expression of GATA-4, but not GATA-6, is stimulated by exogenous gonadotropins in cultured gonadal cell lines $(31,33)$. Furthermore, downregulation of GATA-4 expression accompanies follicular atresia caused by the mechanism of programmed cell death. In testis, GATA-4 and GATA- 6 expression are most abundant at the proliferative stage of Sertoli cells, suggesting a role in the expansion of these cells $(32,33)$. Taken together, these studies imply overlapping but distinct functions for GATA-4 and GATA-6 in the hypothalamic-pituitary-gonadal axis, and suggest that the relative expression of these factors within these tissues may regulate hormonal signaling or cell proliferation.

Given the expression and regulation of GATA-4 and GATA- 6 in the gonads, it was of 
interest to explore their expression in the adrenals, which share expression of many developmentally and functionally important genes, including inhibin, SF-1 and DAX-1 (36 and references therein) with the gonads. We have also utilized the transgenic mouse model described above, and human pathological samples to explore the role of GATA-4 and GATA-6, in adrenocortical tumorigenesis. Abundant GATA- 6 mRNA was found in adrenal cortex during mouse development, whereas GATA-4 mRNA was undetectable. In striking contrast to the findings in normal adrenal gland, GATA- 6 was absent from murine adrenocortical tumors, while GATA-4 mRNA expression was dramatically upregulated in these mouse tumors as well as in human adrenocortical carcinomas.

\section{Materials and Methods}

Mouse Stocks

Normal adrenal glands were obtained from 7-week-old male C57BL/6J mice (Jackson Labs, Bar Harbor, ME). Mouse embryos were obtained by mating male and female B6DJLF1/J mice. For estimating embryonal age, noon of the day on which the copulation plug was found was considered as 0.5 days p.c. Precise staging of dissected embryos was performed using The Atlas of Mouse Development (37). The inhibin $\alpha$-subunit promoter/SV40 $\mathrm{T}$-antigen transgenic mice have been described previously $(17,18,20)$.

\section{In Vivo Manipulations of Adrenal Function}

To study the hormonal regulation of GATA-4 and GATA- 6 in the adrenal gland we treated mice (three animals in each group) with intraperitoneal injection of the following agents: ACTH $10 \mu \mathrm{g} / \mathrm{kg}$ body weight in one dose 2 hours prior to organ harvest, and dexamethasone 0.03 $\mathrm{mg} / \mathrm{kg}$ body weight daily for either 2 days (acute suppression) or 5 days (chronic suppression) starting 3 or 6 days prior to organ harvest, respectively. Adrenal glands were harvested also from a group of animals at evening to assess possible diurnal variation in GATA-4/-6 expression. The RNA isolated from the adrenals of these animals was studied for GATA-4 and GATA- 6 expression by RNase protection.

\section{Human Samples}

Paraffin-embedded tissue samples originally collected for diagnostic purposes were analyzed for their expression of GATA-4 protein. These samples originated from 3 cases of ACC ( 2 females, 1 male, aged 35-78 yr), 5 cases of benign adrenal adenomas ( 3 females, 2 males, aged $48-73$ yr) and 4 cases of pheochromocytomas ( 3 females, 1 male, aged 12-68 yr).

\section{Adrenal Cell Cultures and Hormonal Stimulation of the Cell Lines}

An immortalized cell line, termed $C \alpha 1$, derived from an adrenocortical tumor in a transgenic mouse line bearing the mouse inhibin $\alpha$-subunit promoter/Simian virus $40 \mathrm{~T}$-antigen fusion gene, has been described elsewhere (20). The cells were cultured on plastic dishes in HEPES (20 mmol/l) buffered Dulbecco's Modified Essential Media (DMEM) with GlutaMAX®/F12 1:1 (Gibco BRL, Paisley, Scotland) supplemented with $10 \%$ heat-inactivated fetal calf serum (FCS, Biochlear, Berks, U.K.), glucose $(4.5 \mathrm{~g} / \mathrm{l})$ and gentamicin $(100 \mathrm{mg} / \mathrm{l})$. Cells were used in immunohistochemistry after 2-3 days in culture. Untreated $\mathrm{C} \alpha \mathrm{l}$ cells or cells treated with ACTH $(50 \mathrm{ng} / \mathrm{ml})$ were collected for RNA isolation and Northern hybridization performed as described later.

\section{In Situ Hybridization}

Mouse embryos or adrenal glands were washed briefly in PBS and then frozen in O.C.T. cryopreservation solution (Tissue Tek®, Miles Inc., Elkhart, IN). Mouse adrenal tumors were fixed with $4 \%$ paraformaldehyde and embedded in paraffin. Frozen sections $(10 \mu \mathrm{m})$ were fixed in $4 \%$ paraformaldehyde in PBS, or sections ( 10 $\mu \mathrm{m})$ from paraffin embedded tissues were subjected to in situ hybridization as described (38). Tissue sections were incubated with $1 \times 10^{6}$ CPM of $\left[{ }^{33} \mathrm{P}\right]$-labeled (1000-3000 Ci/mmol, Amersham, Life Technologies, Arlington Heights, IL) antisense or sense riboprobe in a total volume of $80 \mu \mathrm{l}$. Antisense and sense riboprobes for GATA- 4 and GATA- 6 were prepared as described elsewhere $(27,31,39)$.

\section{Northern Hybridization}

Total RNA was isolated using guanidinium thiocyanate-phenol-chloroform extraction and analyzed for expression of GATA-4 or GATA- 6 mes- 
sage using Northern hybridization (27). Twenty micrograms of denaturated total RNA was subjected to electrophoresis on $1 \%$ denaturing agarose gel and then transferred onto nylon membranes (Hybond N, Amersham, Arlington Heights, IL). The membranes were hybridized with $\left[{ }^{32} \mathrm{P}\right]$ labeled RNA probes for GATA-4 (27) or GATA-6 (29). Hybridization and washing of the membranes were performed as previously described (27).

Hybridization signals were detected by autoradiography using Kodak X-Omat AR Diagnostic film XAR5. Autoradiograms were scanned by the Microcomputer Imaging device (MCID, version 1.2, from Imaging Research, Inc., St. Catherines, Ontario, Canada) to quantify messenger RNA (mRNA) species. The intensities of specific bands were quantified using Tina software (Raytest, Straubenhardt, Germany). The results were expressed in arbitrary densitometric units (percent of the control value) corrected according to the intensity of $28 \mathrm{~S}$ ribosomal subunit in the gel stained with ethidium bromide. Statistical analyses were performed on the basis of three independent experiments. The data were analyzed by one-way ANOVA, using a Macintosh version of the SuperANOVA program (Abacus Concepts, Inc., Berkeley, CA), followed by Duncan's new multiple range and Fisher's protected last significant differences post-hoc tests. $P<0.05$ was considered statistically significant. The results shown in the figures represent the mean \pm SEM.

\section{RNase Protection Assay}

RNA from adrenal and ovarian tissue was used for RNase protection assays performed with a commercially available kit (Ambion, Austin, TX) using $10 \mu \mathrm{g}$ of total RNA. [ ${ }^{32} \mathrm{P}$ ]labeled $(800 \mathrm{Ci} /$ mmol, Amersham Life Technologies, Arlington Heights, IL) antisense riboprobe recognizing transcripts arising from exons II and III of the Gata4 gene was prepared by in vitro transcription of NotI linearized G14A plasmid (27) using T7 RNA polymerase and $\left[\alpha-{ }^{32} \mathrm{P}\right] \mathrm{CTP}(650 \mathrm{Ci} / \mathrm{mmol}$, ICN Pharmaceuticals Inc., Costa Mesa, CA). Antisense GATA-6 riboprobe was prepared from pCR II mGATA-6 plasmid (29) linearizing with PstI and using SP6 RNA polymerase. Antisense $\beta$-actin probe was prepared according to the manufacturer's recommendations (Ambion, Austin, TX). The sizes of full-length and protected RNA probes were as follows: GATA-4, 491 and 430 nucleotides, GATA-6 140 and $100 \mathrm{nu}-$ cleotides, and $\beta$-actin 300 and 250 nucleotides, respectively.

\section{Immunohistochemistry and Immunocytochemistry}

Frozen tissue sections from mouse adrenals and adrenal tumors, cultured mouse adrenocortical tumor cells (line $\mathrm{C} \alpha \mathrm{l}$ ), and paraffin-embedded human tissue samples were fixed in $4 \%$ paraformaldehyde and subjected to immunohistochemistry using either affinity purified polyclonal rabbit anti-mouse GATA-4 $(27,39)$ or commercial goat polyclonal anti-mouse GATA-4 IgG (Santa Cruz Biotechnology, Santa Cruz, CA) or nonimmune IgG as the primary antibody. A commercially available avidin-biotin immunoperoxidase system was used to visualize bound antibody (Vectastain Elite ABC Kit, Vector Laboratories, Burlingame, CA). 3-amino-9-ethylcarbazole (Sigma Chemicals, St. Louis, MO) was used as the chromogen and the development reaction occurred in the presence of $0.03 \%$ $\mathrm{H}_{2} \mathrm{O}_{2}$. T-antigen was stained with rabbit polyclonal anti-Tag antibody, kindly provided by DR. D. Hanahan, University of California, San Francisco, CA (40), as described (22).

\section{Results \\ GATA-6, but Not GATA-4, Transcripts Are Expressed in Normal Mouse Adrenal Gland}

We first wanted to address the normal developmental pattern of GATA-4 and GATA- 6 expression in the adrenal gland. In initial experiments, we examined the expression of GATA-4 and GATA-6 in normal mouse adrenal gland using RNA analysis. In situ hybridization revealed abundant expression of GATA-6 message in postnatal adrenal cortex (Fig. 1A, B). GATA-6 mRNA was uniformly distributed throughout the zones of the adrenal cortex, but no GATA-6 message was evident in the adrenal medulla. When in situ hybridization for GATA-4 was performed on adjacent tissue sections through normal adrenal gland, no GATA-4 message was detected (Fig. 1C, D). Similar results were obtained in in situ hybridizations performed on fetal (day 18 p.c.) adrenals; abundant GATA-6 message was present in the cortex, but it was devoid of GATA-4 mRNA (data not shown). RNase protection assays confirmed these findings; abundant GATA- 6 but no GATA-4 mRNA was detected in normal postnatal adrenal gland (Fig. 1E). 


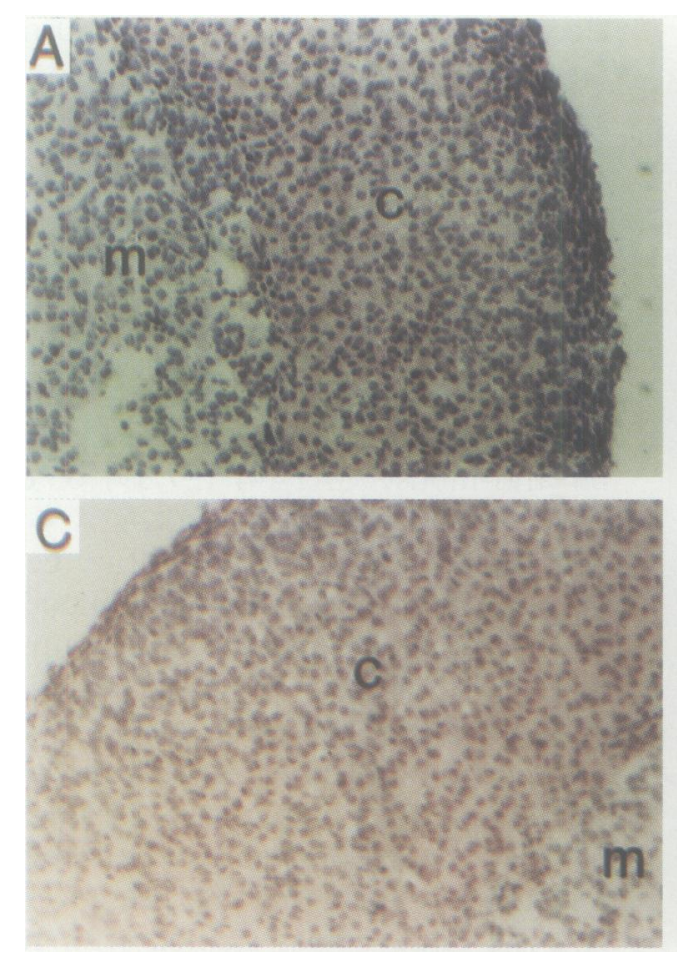

Fig. 1. Expression of GATA-4 and GATA-6 mRNA during adrenal development and in vivo manipulation of adrenal function. HSE (A, C) and dark field views (B, D) of in situ hybridization demonstrating expression of GATA-6 mRNA in the adrenal cortex at postnatal day $25(\mathrm{~A}, \mathrm{~B})$ but not of GATA-4 mRNA (C, D). c, adrenal cortex; m, adrenal medulla. Original magnification $(\times 200)$, bar $=$

\section{Effect of In Vivo Manipulation of Adrenal Function on the Expression of GATA-4 and GATA-6 MRNA}

In vivo stimulation with ACTH for 2 hours (10 $\mu \mathrm{g} / \mathrm{kg}$ ) or suppression with dexamethasone $(0.03 \mathrm{mg} / \mathrm{kg} /$ day for 2 or 5 days) did not result in any marked change in the steady state levels of GATA-6 mRNA in the adrenal gland, as measured by RNase protection assay (Fig. 1E). Neither ACTH nor dexamethasone had any effect on GATA-4 mRNA levels, which remained undetectable (Fig. 1E). No diurnal variation was noted in the expression of GATA- 6 in the adrenals as adrenals harvested in the evening were studied (data not shown); GATA-4 mRNA remained undetected.

\section{GATA-4 is Upregulated and GATA-6 Downregulated in Mouse Adrenocortical Tumors}

To assess whether changes in GATA-4 or GATA-6 expression accompany adrenocortical tumorigenesis, we analyzed inhibin $\alpha$ promoter/

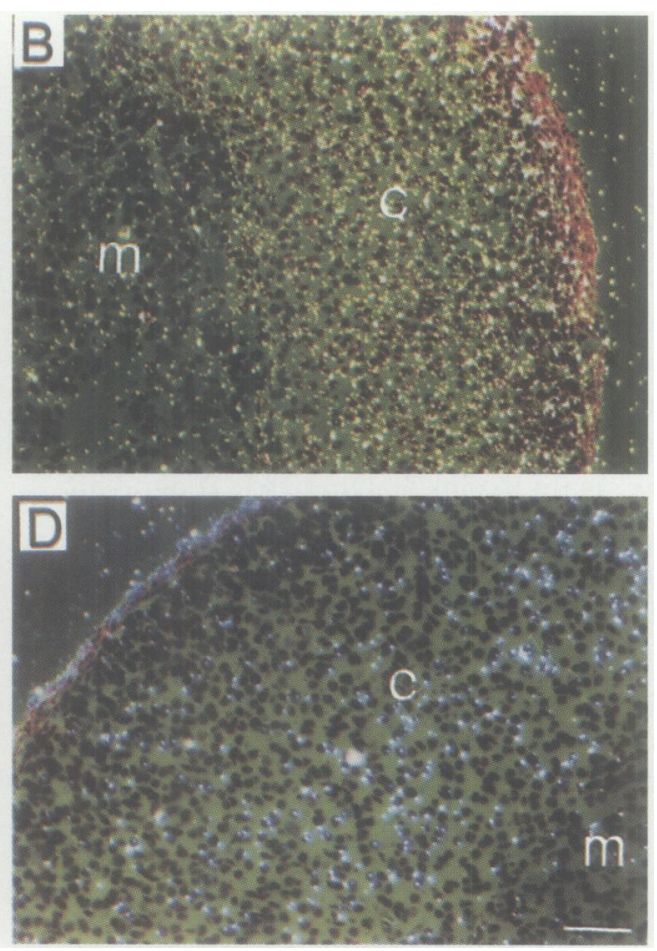

$50 \mu \mathrm{m}$. (E) RNase protection assay showing expression of GATA- 6 mRNA in normal adrenal cortex (Co). No change in the expression level was noted in animals treated with ACTH or short or long treatment with dexamethasone (short- and long dexam., respectively). No GATA-4 mRNA could be detected in the adrenals of control or treated animals. Mouse testis RNA was used as a positive control.

SV40 Tag transgenic mice, developing adrenocortical tumors after gonadectomy (20). In intact and gonadectomized control mice, and in intact transgenic mice, there was no GATA-4 mRNA expression in the adrenal glands (Fig. 2C). With subsequent tumor formation of the gonadectomized transgenic mice there was abundant GATA-4 mRNA in the adrenal tumors (Fig. 2A). In contrast, GATA- 6 mRNA was present in the normal and non-tumorous transgenic adrenal glands, but totally absent in the adrenal tumors (Fig. 2B, C).

In addition to the RNA analysis, we performed immunohistochemistry on adrenal tumors from the transgenic mice. The immunoperoxidase staining revealed uniform staining for GATA-4 protein in the tumor cells, but not in the adjacent normal adrenal tissue (Fig. 2E, F). In keeping with these results, in situ hybridization demonstrates GATA-4, but not GATA-6, mRNA in adrenal tumor tissue (Fig. 2H, I). 


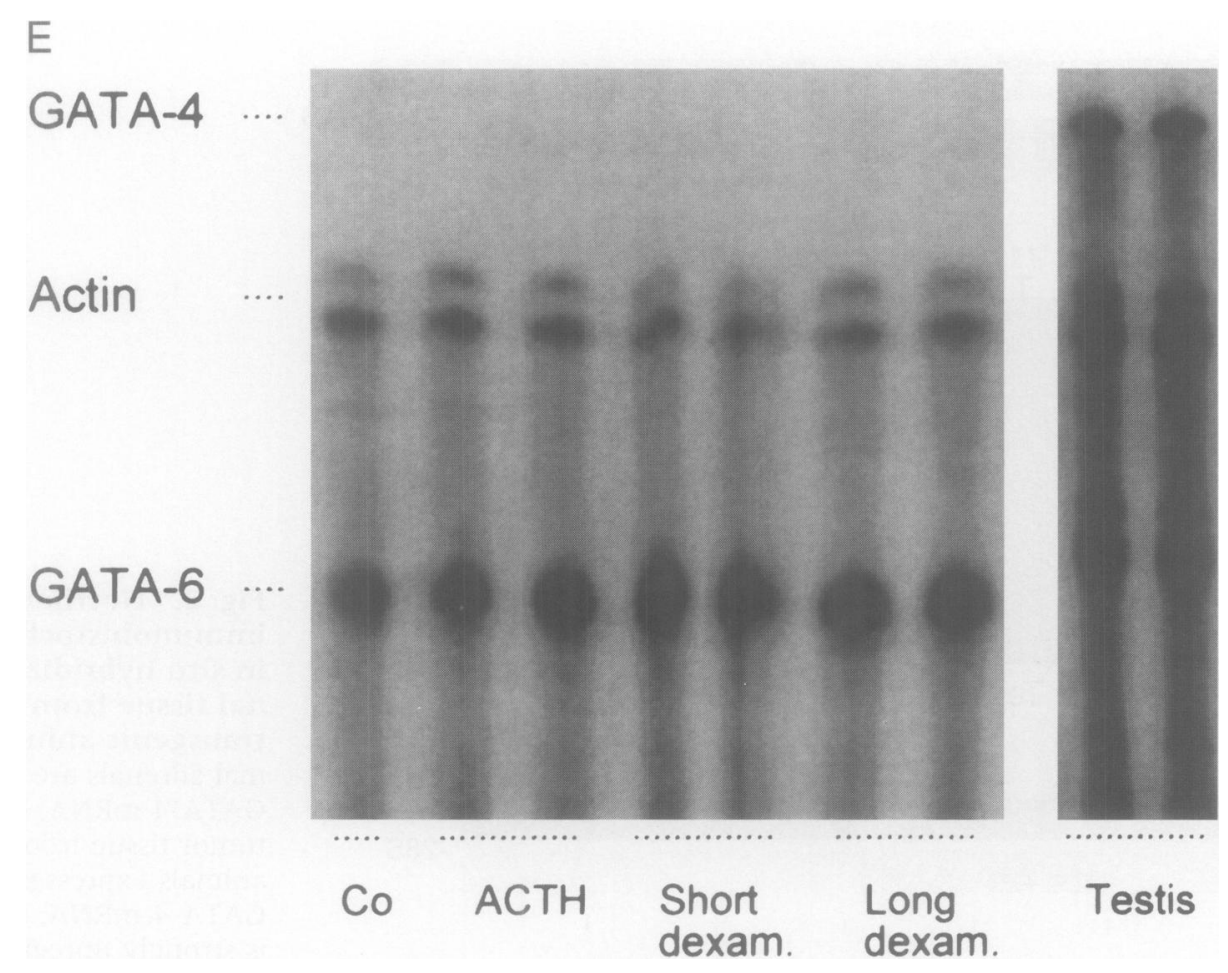

Fig. 1. Continued

GATA-4, but Not GATA-6, Is Expressed in Mouse Adrenocortical Tumor Cell Lines

In addition to examining adrenal tumors of the transgenic mice, we analyzed the adrenocortical cell line $\mathrm{C} \alpha \mathrm{l}$ derived from one of the tumors. Consistent with the observations made on primary tumors, the tumor cell line expressed abundant amounts of GATA-4 mRNA (Fig. 2A) and protein (Fig. 3), but not the GATA-6 message (Fig. 2B). In keeping with the in vivo findings, no change in GATA-4 or GATA-6 mRNA levels was observed when the tumor cell lines were treated with ACTH (data not shown).

\section{GATA-4 Is Present in Human Adrenocortical Carcinomas}

To assess whether the observations made on normal and transgenic mice were relevant to human adrenocortical carcinogenesis, we performed immunohistochemistry for GATA-4 in ACC, adrenal adenomas and pheochromocytomas. We detected nuclear staining for GATA-4 in the tumor tissue from all the three ACC samples examined (Fig. 4A, B), but not in normal adrenal cortex (Fig. 4D, E) nor five adenomas (Fig. 4F, G), nor four pheochromocytomas (Fig. $4 \mathrm{H}, \mathrm{I}$ ). We were unable to assess the presence of GATA- 6 protein in these samples, since no suitable anti-GATA-6 antibodies were available.

\section{Discussion}

This study demonstrates that GATA-4 and GATA- 6 are differentially regulated in normal versus malignant adrenal glands. Whereas GATA-6 expression is related to normal adrenal organogenesis, GATA-4 is expressed in this organ only during tumorigenesis implicating a possible role for this transcription factor in adrenocortical carcinogenesis. This is the first evidence of a link between any GATA binding protein and solid tumors in mammals. Observations of the transgenic adrenals at different stages of the transformation process indicate that GATA-4 expression is specific for the malignant adrenocortical cells, but not for the transgenic $\mathrm{T}$-antigen expression in normal tissue.

Earlier studies on gonadal GATA-4 expression have revealed that abundant expression of this transcription factor is associated with the proliferative phase of ovarian granulosa and testicular Sertoli cells (31-33). The high level of expression in the tumor cells with high proliferative capacity is consistent with this finding. Moreover, studies on ovarian follicular atresia, 

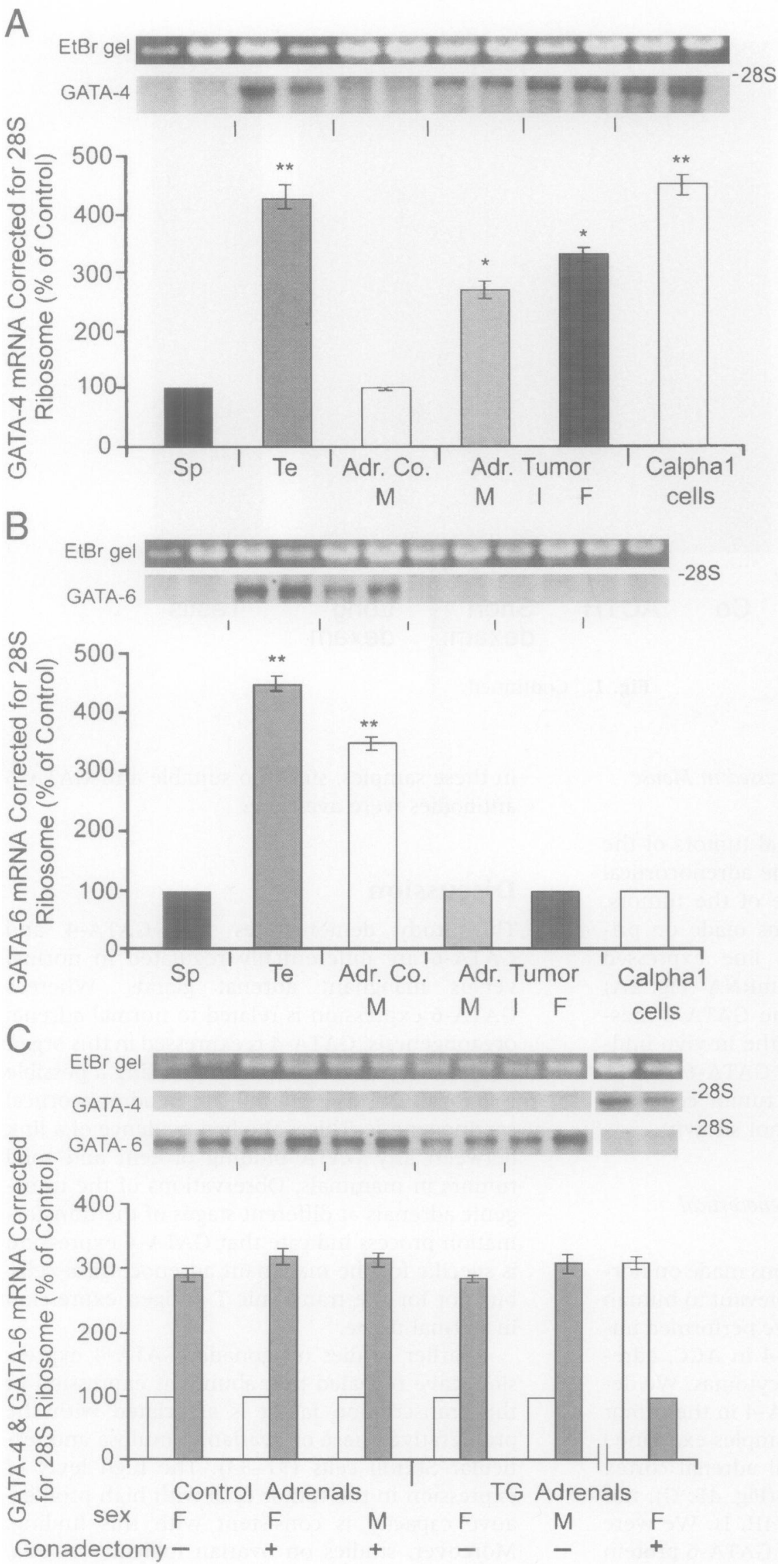

Fig. 2. Northern analysis, immunohistochemistry, and in situ hybridization of adrenal tissue from normal and transgenic animals. (A) Normal adrenals are devoid of GATA-4 mRNA, but adrenal tumor tissue from transgenic animals expresses abundant GATA-4 mRNA; GATA-4 mRNA is strongly upregulated also in the cell line originating from these tumors. (B) In contrast, GATA- 6 mRNA is detected in normal adrenals but not in adrenal tumors or adrenal tumor cell line. (A, B) Normal mouse testis was used as a positive control and spleen as a negative control for GATA-4 mRNA expression. $\mathrm{EtBr}$, ethidium bromide, Sp, spleen; Te, testis; Adr. Co., normal adrenal; Calphal cells, murine adrenal tumor cells; $M$, male; $F$, female. The bars in A\&B show the mean \pm SEM calculated from three independent experiments performed in duplicate. *, $p<$ $0.05 ;{ }^{* *}, p<0.001$ for GATA-4 and GATA- 6 mRNA expression after the indicated treatment vs. that in the spleen (control). (C) GATA-4 mRNA (white column) is absent and GATA-6 (black column) present in the adrenals of normal animals, of normal gonadectomized animals, and of transgenic animals. Whereas GATA-4 is present and GATA-6 absent in the adrenals of gonadectomized transgenic animals, i.e. in adrenal tumors. The upper panel shows representative 28S ribosomal RNA band in the gel stained with EtBr, and Northern blots for GATA-4 and GATA-6. TG Adrenals, the adrenals of the transgenic mice; $F$, female; $M$, male. 

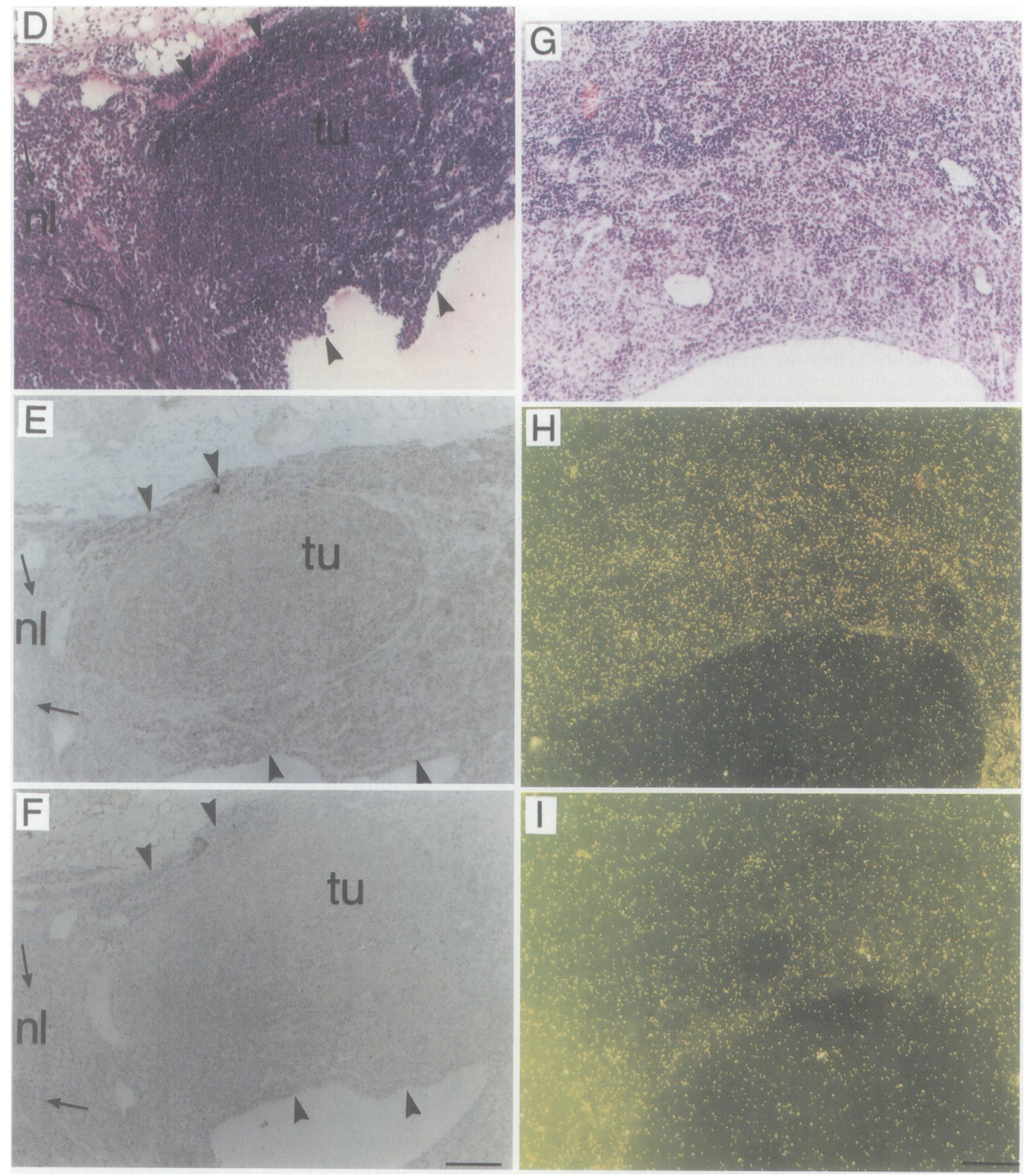

Fig. 2. Continued (D-F) Immunoperoxidase staining shows the presence of GATA-4 protein in the adrenal tumor tissue (tu, arrowheads). A small area of normal adrenal tissue can be seen on the edge of the tissue sample (nl, arrows); (D) HEE staining of the tumor; (E) immunoperoxidase staining for GATA-4; (F) control staining with nonimmune serum. Origi-

nal magnification $(\times 100)$, bar $=100 \mu \mathrm{m}$. $(\mathrm{G}-\mathrm{I})$ In situ hybridization demonstrates the presence of GATA-4 mRNA (H) in adrenal tumor tissue, whereas it is essentially devoid of GATA-6 mRNA (I); (G) HEE staining of adjacent section. Original magnification $(\times 100)$, bar $=100 \mu \mathrm{m}$. 


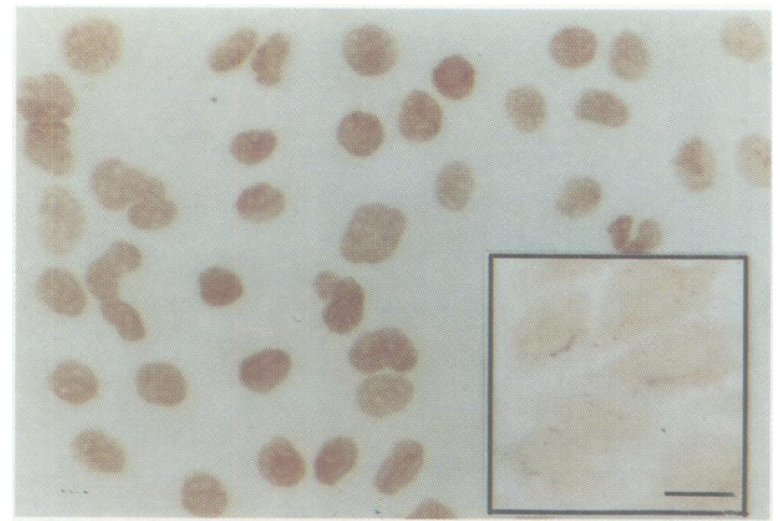

Fig. 3. Immunohistochemistry for GATA-4 in adrenal tumor cells from transgenic animals. Immunohistochemistry of cultured mouse adrenal cell line reveals strong nuclear staining with antiGATA-4 antibodies, but not with preimmune serum (inset). Original magnification $(\times 400)$, bar $=20$ $\mu \mathrm{m}$.

occurring through apoptosis, demonstrated downregulation of GATA-4 mRNA in association with programmed cell death (31). It is tempting to speculate that GATA-4 could act as a cell survival factor during the transformation so that the maintenance of expression of this transcription factor could enhance tumor progression and growth.

To fully understand the roles of GATA-4 and GATA- 6 in normal and malignant adrenal development, it will be necessary to define the regulation and target genes for these transcription factors in this organ. The combined evidence from this study and earlier observations in the gonad shows that these transcription factors are present at the sites of steroidogenesis, and more importantly also at the time of active steroidogenesis in these organs, in particular in fetal and adult testis and adrenal. These findings suggest a role for GATA-4 and/or GATA-6 in steroidogenesis. Some genes for the steroidogenic enzymes, for example that of aromatase, harbor putative GATA-binding sites in the regulatory elements of their genes (41), and are thus candidate targets for GATA proteins expressed in endocrine organs. Several other genes, such as anti-Müllerian hormone, inhibin $\alpha$, and brain type natriuretic peptide have been proposed as potential target genes for GATA-4 or GATA- 6 in ovary and testes $(32,33,42,43)$. In hypothalamus, GATA-4 has been implicated in the regulation of GnRH gene $(34,35,44)$. Rigorous genetic studies would, however, be required to establish the in vivo target genes for GATA-4 and GATA- 6 in the endocrine system. Unfortunately, the published models of homozygous null mutations in GATA4 $(45,46)$ and GATA6 $(47)$ gene cause early embryonic lethality, which precludes analysis of the role of these transcription factors in adrenal development.

The regulatory mechanisms in the adrenal tumorigenesis of the transgenic mouse model are still unknown, but recent evidence shows that suppression of gonadotropins in these animals inhibits tumor formation (21). Although gonadotropin receptors are not present in normal adrenal gland, $\mathrm{LH}$ receptors were expressed in the adrenal tumors (22). Of interest, our results in gonadal tumor cell lines showed that gonadotropins upregulate GATA-4 mRNA $(31,33)$. Specifically these studies showed upregulation of GATA-4, but not GATA-6, in Sertoli and granulosa cell lines by FSH and in Leydig cell lines by hCG. It is thus possible that the signal triggered by LH in the LHR-bearing adrenal tumor cells acts through GATA-4, which may then participate in the events leading to malignant phenotype in these cells. Our preliminary data supports the association of LH receptor and GATA-4 expression in the tumorous adrenals.

The reciprocal changes in GATA-4 and GATA- 6 expression associated with adrenocortical tumorigenesis are consistent with earlier studies showing that GATA-4 can influence expression of GATA-6 and vice versa. In GATA4-/embryos $(45,46)$ and cell lines $(48)$ there is upregulation of GATA-6 mRNA expression, while in GATA6-/- embryos (47) there is decreased expression of GATA-4 mRNA. The molecular mechanisms for this cross-regulation are not known.

The current findings, in particular those on the human tumors, may also offer new tools for the diagnosis of adrenal tumors. There are no reliable cytologic criteria for distinguishing adrenocortical carcinomas from adenomas or renal cell carcinomas by light microscopy (49), although certain morphological features have been suggested to be typical for ACC (50). In addition, adrenocortical carcinoma can mimic benign lesions histologically (51). Immunocytochemistry of 3-beta-hydroxysteroid dehydrogenase and adrenal-4-binding protein (SF1), a transcription factor implicated in the regulation of steroidogenesis, may be useful in the differential diagnosis between adrenocortical and renal cell carcinomas by identifying adrenocortical parenchymal cells (49). Nuclear 


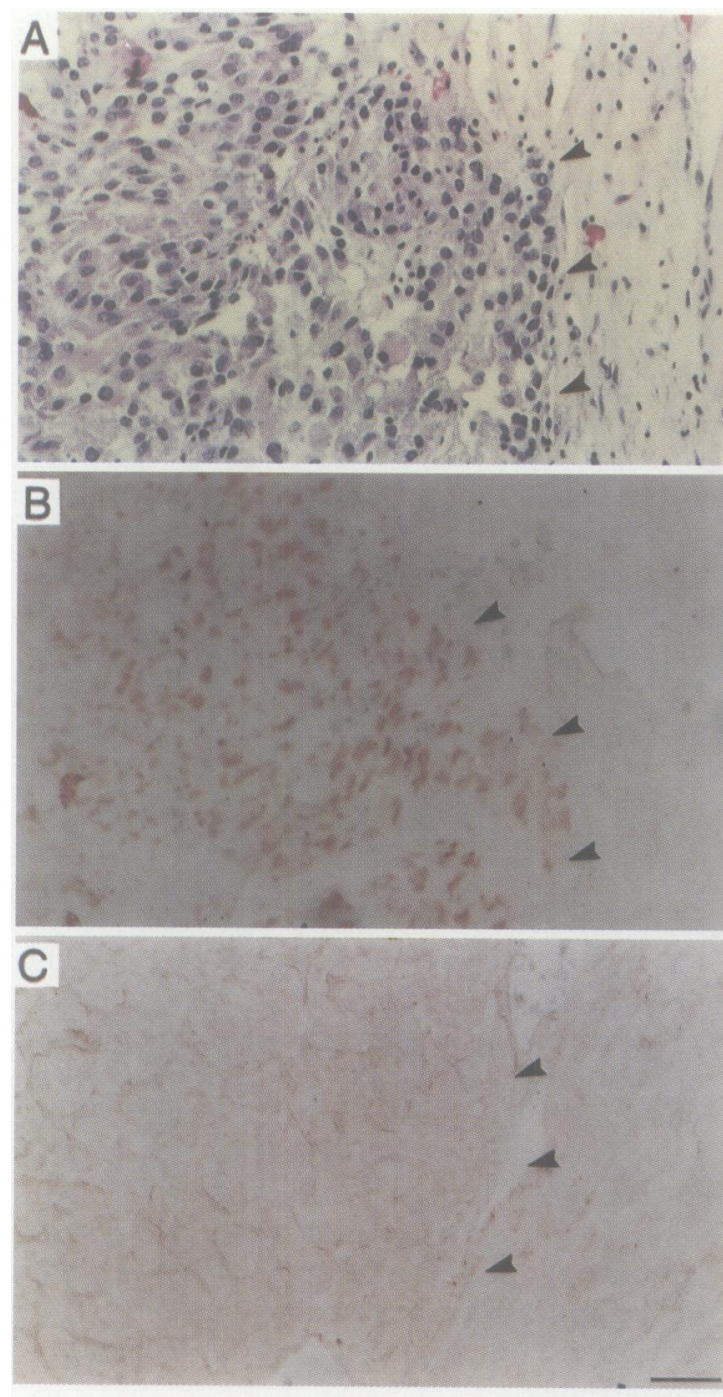

Fig. 4. Immunohistochemistry for GATA-4 in human adrenal tissue. H\&E staining and immunoperoxidase staining for GATA-4 from consecutive sections of adrenocortical carcinomas (A, B), normal adrenal cortex $(D, E)$, adenomas $(F, G)$ and pheochromocytomas $(\mathrm{H}, \mathrm{I})$; (C) control staining with
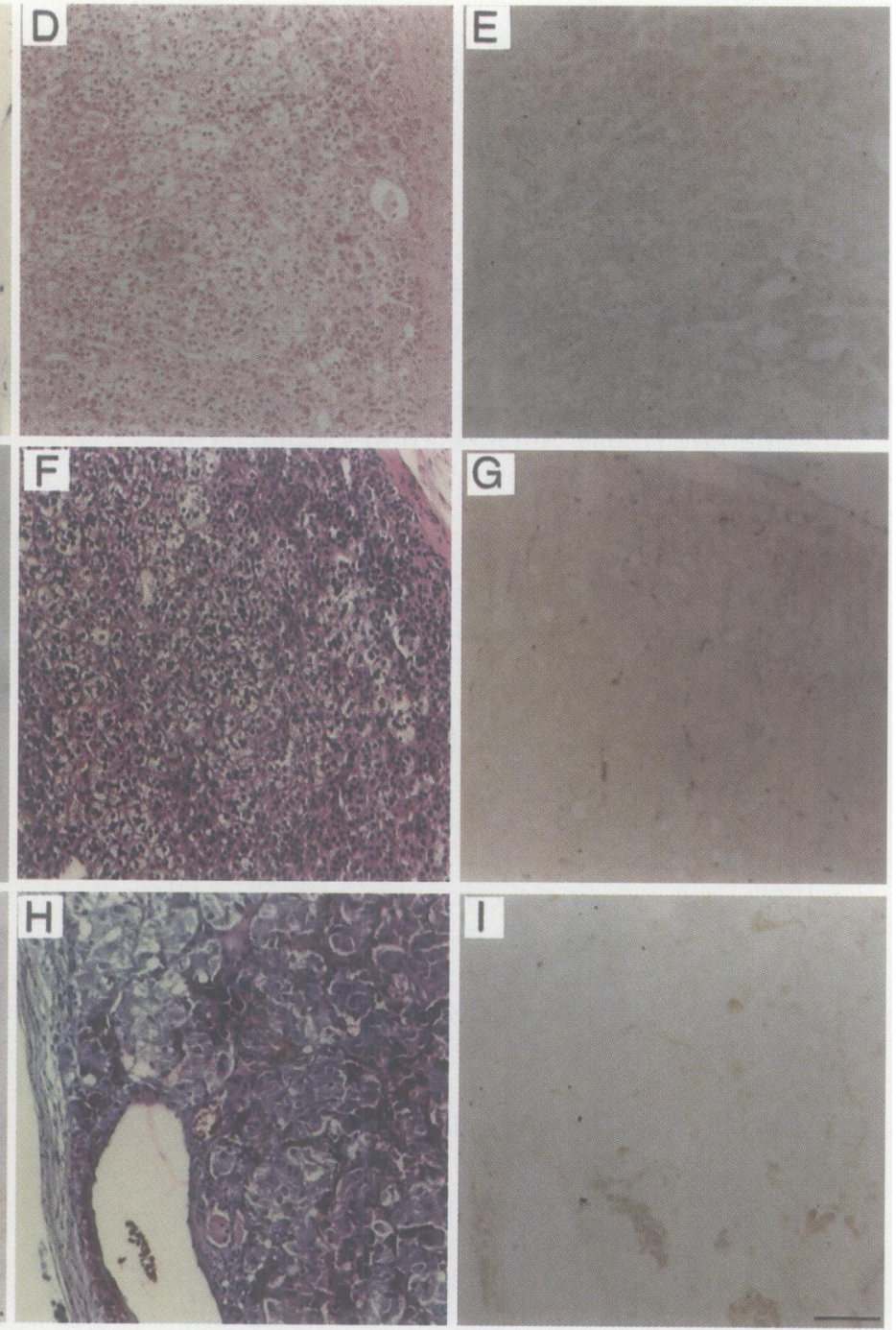

nonimmune serum (ACC). GATA-4 protein is abundantly present in the nuclei of carcinoma cells (A-C, arrowheads), but absent from normal cortex, adenomas, and pheochromocytomas. Original magnifications $(\times 200)$ for $(A-C)$, bar $=50 \mu \mathrm{m} ;(\times 100)$ for $(\mathrm{D}-\mathrm{I})$, bar $=100 \mu \mathrm{m}$.

\section{Acknowledgments}

has also been shown to be useful for discriminating ACC from intraadrenal metastases and adrenomedullary tumors (52). We are now in the process of further evaluating the roles of GATA transcription factors in human adrenal neoplasia. Based on the present findings in the normal and malignant human adrenal tissue, we propose that immunohistochemical detection of GATA-4 might serve as a new nuclear marker to discriminate between malignant and benign adrenal tumors.
This work was supported by Juselius Foundation (ITH, DBW, and MH), the Finnish Cancer Foundation (ITH), the Finnish Pediatric Foundation $(\mathrm{MH})$, the University Central Hospital in Helsinki (SK, SS, and MH), the NIH (LJM), a Burroughs Wellcome Fund Career Development Award (LJM), Pediatric Cardiology SCOR HL61006 (DBW), the Washington University MonsantoSearle Agreement (DBW), and an Established Investigator Award from the AHA (DBW). 


\section{References}

1. Wagner J, Portwine C, Rabin K, Leclerc JM, Narod SA, Malkin D. (1994) High frequency of germline p53 mutations in childhood adrenocortical cancer. J. Natl. Cancer Inst. 86: 1707-1710.

2. Cutler SJ, Young JL (eds). (1975) Biometrics Branch, National Cancer Institute, Third National Cancer Survey: incidence data. National Cancer Institute Monograph 41. Government Printing Office, Washington, D.C.

3. Sabbaga CC, Avilla SG, Schulz C, Garbers JC, Blucher D. (1994) Adrenocortical carcinoma in children: clinical aspects and prognosis. J. Pediatr. Surg. 28: 841-843.

4. Boscaro M, Fallo F, Barzon L, Daniele O, Sonino N. (1995) Adrenocortical carcinoma: epidemiology and natural history. Minerva Endocrinol. 20: 89-94.

5. Haak HR, Hermans J, van de Velde CJ, et al. (1994) Optimal treatment of adrenocortical carcinoma with mitotane: results in a consecutive series of 96 patients. Brit. J. Cancer 69: 947-951.

6. Favia G, Lumachi F, Carraro P, D'Amico DF. (1995) Adrenocortical carcinoma. Our experience. Minerva Endocrinol. 20: 95-99.

7. Dogliotti L, Berruti A, Pia A, Paccotti P, Ali A, Angeli A. (1995) Cytotoxic chemotherapy for adrenocortical carcinoma. Minerva Endocrinol. 20: 105-109.

8. Kasperlik-Zaluska AA, Migdalska BM, Zgliczynski S, Makowska AM. (1995) Adrenocortical carcinoma. A clinical study and treatment results of 52 patients. Cancer 75: 2587-2591.

9. Beuschlein F, Reincke M, Karl M, et al. (1994) Clonal composition of human adrenocortical neoplasms. Cancer Res. 54: 4927-4932.

10. Li FP, Fraumeni Jr JF, Mulvihill JJ, et al. (1988) A cancer family syndrome in twenty-four kindreds. Cancer Res. 48: 5358-5362.

11. Wiedemann HR. (1983) Tumours and hemihypertrophy associated with Wiedeman-Beckwith syndrome. Eur. J. Pediatr. 141: 129.

12. Birch JM, Hartley AL, Tricker KJ, et al. (1994) Prevalence and diversity of constitutional mutations in the p53 gene among 21 Li-Fraumeni families. Cancer Res. 54: 1298-1304.

13. Miyamoto H, Kubota $Y$, Shuin T, Shiozaki $H$. (1996) Bilateral adrenocortical carcinoma showing loss of heterozygosity at the p53 and RB gene loci. Cancer Genet. Cytogenet. 88: 181-183.

14. Hatada I, Ohashi H, Fukushima Y, et al. (1996) An imprinted gene p57KIP2 is mutated in BeckwithWiedemann syndrome. Nat. Genet. 14: 171-173.

15. Skogseid B, Larsson C, Lindgren P-G, et al. (1992) Clinical and genetic features of adrenocortical lesions in multiple endocrine neoplasia type 1 . J. Clin. Endocrinol. Metab. 75: 76-81.

16. Haak HR, Fleuren GJ. (1995) Neuroendocrine dif- ferentiation of adrenocortical tumors. Cancer 75 : 860-864.

17. Kananen K, Markkula M, Rainio E, Su J-GJ, Hsueh AJW, Huhtaniemi IT. (1995) Gonadal tumorigenesis in transgenic mice bearing the mouse inhibin $\alpha$-subunit promoter/Simian virus T-antigen fusion gene: characterization of ovarian tumors and establishment of gonadotropin-responsive granulosa cell lines. Mol. Endocrinol. 9: 616627.

18. Kananen $\mathrm{K}$, Markkula $\mathrm{M}$, el Hefnawy $\mathrm{T}$, et al. (1996) The mouse inhibin $\alpha$-subunit promoter directs SV40 T-antigen to Leydig cells in transgenic mice. Mol. Cell. Endocrinol. 119: 135-146.

19. Rahman NA, Kananen $K$, Rilianawati $X$, et al. (1998) Transgenic mouse models for gonadal tumorigenesis. Mol. Cell. Endocrinol. 145: 167-174.

20. Kananen K, Markkula M, Mikola M, Rainio E-M, McNeilly A, Huhtaniemi I. (1996) Gonadectomy permits adrenocortical tumorigenesis in mice transgenic for the mouse inhibin $\alpha$-subunit promoter/Simian virus $\mathrm{T}$-antigen fusion gene: evidence for negative autoregulation of the inhibin $\alpha$-subunit gene. Mol. Endocrinol. 10: 1667-1677.

21. Kananen K, Rilianawati X, Paukku T, Markkula M, Rainio E-M, Huhtaniemi I. (1997) Suppression of gonadotropins inhibits gonadal tumorigenesis in mice transgenic for the mouse inhibin $\alpha$-subunit promoter/Simian virus T-antigen fusion gene. Endocrinology 138: 3521-3531.

22. Rilianawati X, Paukku T, Kero J, et al. (1998) Direct luteinizing hormone action triggers adrenocortical tumorigenesis in castrated mice transgenic for the murine inhibin $\alpha$-subunit promoter/Simian virus $40 \mathrm{~T}$-antigen fusion gene. Mol. Endocrinol. 12: 801-809.

23. deLange WE, Pratt JJ, Doorenbos H. (1980) A gonadotropin-responsive testosterone producing adrenocortical adenoma and high gonadotropin levels in an elderly woman. Clin. Endocrinol. 12: 21-28.

24. Leinonen $P$, Ranta $T$, Siegberg R, Heikkilä $P$, Kahri A. (1991) Testosterone secreting virilizing adrenal adenoma with human chorionic gonatropin receptors and 21-hydroxylase deficiency. Clin. Endocrinol. 34: 31-35.

25. Orkin SH. (1992) GATA-binding transcription factors in hematopoietic cells. Blood 80: 575-581.

26. Evans T. (1997) Regulation of cardiac gene expression by GATA-4/5/6. Trends Card. Med. 7: 7583.

27. Arceci RJ, King AAJ, Simon MC, Orkin SH, Wilson DB. (1993) Mouse GATA-4: a retinoic acidinducible GATA-binding transcription factor expressed in endodermal derivatives and heart. Mol. Cell Biol. 13: 2235-2246.

28. Laverriere AC, MacNeill C, Mueller C, Poelman RE, Burch JBE, Evans T. (1994) GATA4/5/6, a subfamily of three transcription factors tran- 
scribed in developing heart and gut. J. Biol. Chem. 269: 23177-23184.

29. Narita N, Heikinheimo M, Bielinska M, White RA Wilson DB. (1996) The gene for transcription factor GATA-6 resides on mouse chromosome 18 and is expressed in myocardium and vascular smooth muscle. Genomics 36: 345-348.

30. Morrisey EE, Ip HS, Lu MM, Parmacek MS. (1996) GATA-6: a zinc finger transcription factor that is derived from lateral mesoderm. Dev. Biol. 177: 309-322.

31. Heikinheimo $\mathbf{M}$, Ermolaeva $M$, Bielinska $M$, et al. (1997) Expression and hormonal regulation of transcription factors GATA-4 and GATA- 6 in the mouse ovary. Endocrinology 138: 3505-3514.

32. Viger RS, Mertineit C, Trasler JM, Nemer $M$. (1998) Transcription factor GATA-4 is expressed in asexually dimorphic pattern during mouse gonadal development and is a potent activator of the Müllerian inhibiting substance. Development 125: 2665-2675.

33. Ketola I, Rahman N, Toppari J, et al. (1999) Expression and regulation of transcription factors GATA-4 and GATA-6 in developing mouse testis. Endocrinology 140: 1470-1480.

34. Lawson MA, Mellon PL. (1998) Expression of GATA-4 in migrating gonadotropin-releasing neurons of the developing mouse. Mol. Cell. Endocrin. 140: 157-161.

35. Lawson MA, Buhain AR, Jovenal JC, Mellon PL. (1998) Multiple factors interacting with GATA sites of the gonadotropin releasing hormone neuron specific enhancer regulate gene expression. Mol. Endocrin. 12: 364-377.

36. Parker KL, Schimmer BP. (1997) Steroidogenic factor 1: a key determinant of endocrine development and function. Endocrin. Rev. 18: 361-377.

37. Kaufman MH. (1992) The Atlas of Mouse Development. London: Academic Press.

38. Wilkinson DG. (1992) Whole mount in situ hybridization of vertebrate embryos. In: Wilkinson DG (ed), In situ Hybridization-A Practical Approach. IRL Press, Oxford, pp. 75-83.

39. Heikinheimo M, Scandrett J, Wilson DB. (1994) Localization of transcription factor GATA-4 to regions of mouse embryo involved in cardiac development. Dev. Biol. 164: 361-373.

40. Efrat S, Hanahan D. (1987) Bidirectional activity of the rat insulin II $5^{\prime}$ flanking region in transgenic mice. Mol. Cell. Biol. 7: 192-198.

41. Richards JS. (1994) Hormonal control of gene expression in the ovary. Endocrin. Rev. 15: 725751.

42. Yomodiga $\mathrm{K}$, Ohtani H, Harigae $\mathrm{H}$, et al. (1994) Developmental stage- and spermatogenic cyclespecific expression of transcription factor GATA-1 in mouse Sertoli cells. Development 120: 17591766.

43. Grépin C, Dagnino L, Robitaille L, Haberstroh L, Antakly T, Nemer M. (1994) A hormone-encoding gene identifies a pathway for cardiac but not skeletal muscle gene transcription. Mol. Cell. Biol. 14: 3115-3129.

44. Lawson MA, Whyte DB, Mellon PL. (1996) GATA factors are essential for activity of the neuronspecific enhancer of the gonadotropin-releasing hormone gene. Mol. Cell. Biol. 16: 3596-3605.

45. Kuo CT, Morrisey EE, Anandappa R, et al. (1997) GATA4 transcription factor is required for ventral morphogenesis and heart tube formation. Genes Dev. 11: 1048-1060.

46. Molkentin JD, Lin Q, Duncan SA, Olson EN. (1997) Requirement of the transcription factor GATA4 for heart tube formation and ventral morphogenesis. Genes Dev. 11: 1061-1072.

47. Morrisey EE, Tang Z, Sigrist $\mathrm{K}$, et al. (1998) GATA6 regulates HNF4 and is required for differentiation of visceral endoderm in the mouse embryo. Genes Dev. 12: 3579-3590.

48. Bielinska M, Wilson DB. (1997) Introduction of yolk sac endoderm in GATA-4 deficient embryoid bodies by retinoic acid. Mech. Devel. 65: 43-54.

49. Sasano H, Shizawa S, Nagura H. (1995) Adrenocortical cytopathology. Am. J. Clin. Pathol. 104: 161-166.

50. Sharma S, Singh R, Verma K. (1997) Cytomorphology of adrenocortical carcinoma and comparison with renal cell carcinoma. Acta Cytol. 41: 385392.

51. Chan JK, Tsang WY. (1995) Endocrine malignancies that may mimic benign lesions. Semin. Diagn. Pathol. 12: 45-63.

52. Tartour E, Caillou B, Tenenbaum F, et al. (1993) Immunohistochemical study of adrenocortical carcinoma. Predictive value of the D11 monoclonal antibody. Cancer 72: 3296-3303. 